\title{
Short-chain chlorinated paraffins in soil, paddy seeds (Oryza sativa) and snails (Ampullariidae) in an e-waste dismantling area in China: Homologue group pattern, spatial distribution and risk assessment ${ }^{\text {th }}$
}

\author{
Bo Yuan ${ }^{\text {a, }}{ }^{\text {, Jianjie Fu }}{ }^{\text {a }}$, Yawei Wang a, b, c, *, Guibin Jiang ${ }^{\text {a }}$ \\ a State Key Laboratory of Environmental Chemistry and Ecotoxicology, Research Center for Eco-Environmental Sciences, Chinese Academy of Sciences, \\ Beijing 100085, China \\ ${ }^{\mathrm{b}}$ Institute of Environment and Health, Jianghan University, Wuhan 430056, China \\ ${ }^{\mathrm{c}}$ University of Chinese Academy of Sciences, Beijing 100049, China
}

\section{A R T I C L E I N F O}

\section{Article history:}

Received 21 July 2016

Received in revised form

29 September 2016

Accepted 4 October 2016

Available online 15 October 2016

\section{Keywords:}

Short-chain chlorinated paraffins (SCCPs)

E-waste dismantling area

Environmental-matrix distribution

Spatial distribution

Dietary exposure

\begin{abstract}
A B S T R A C T
Short-chain chlorinated paraffins (SCCPs) in multi-environmental matrices are studied in Taizhou, Zhejiang Province, China, which is a notorious e-waste dismantling area. The investigated matrices consist of paddy field soil, paddy seeds (Oryza sativa, separated into hulls and rice unpolished) and apple snails (Ampullariidae, inhabiting the paddy fields). The sampling area covered a $65-\mathrm{km}$ radius around the contamination center. $C_{10}$ and $C_{11}$ are the two predominant homologue groups in the area, accounting for about $35.7 \%$ and $33.0 \%$ of total SCCPs, respectively. SCCPs in snails and hulls are generally higher than in soil samples (30.4-530 ng/g dw), and SCCPs in hulls are approximate five times higher than in corresponding rice samples $(4.90-55.1 \mathrm{ng} / \mathrm{g} \mathrm{dw})$. Homologue pattern analysis indicates that paddy seeds (both hull and rice) tend to accumulate relatively high volatile SCCP homologues, especially the ones with shorter carbon chain length, while snails tend to accumulate relatively high lipophilic homologues, especially the ones with more substituted chlorines. SCCPs in both paddy seeds and snails are linearly related to those in the soil. The e-waste dismantling area, which covers a radius of approximate $20 \mathrm{~km}$, shows higher pollution levels for SCCPs according to their spatial distribution in four matrices. The preliminary assessment indicates that SCCP levels in local soils pose no significant ecological risk for soil dwelling organisms, but higher risks from dietary exposure of SCCPs are suspected for people living in ewaste dismantling area.
\end{abstract}

() 2016 Elsevier Ltd. All rights reserved.

\section{Introduction}

Chlorinated paraffins (CPs) are important industrial chemicals, classifying as short-chain (SCCPs, $\mathrm{C}_{10-13}$ ), medium-chain (MCCPs, $\mathrm{C}_{14-17}$ ) and long-chain chlorinated paraffins (LCCPs, $\mathrm{C}_{\geq 18}$ ). CPs have been widely produced for use as plasticizers, leather fatliquors, sealants, and flame retardants in the past decades (Bayen et al., 2006). Among these three groups of man-made chemical products, SCCPs are the most concerning regarding environmental fate,

\footnotetext{
* This paper has been recommended for acceptance by Charles Wong.

* Corresponding author. State Key Laboratory of Environmental Chemistry and Ecotoxicology, Research Center for Eco-Environmental Sciences, Chinese Academy of Sciences, P.O. Box 2871, Beijing 100085, China.

E-mail address: ywwang@rcees.ac.cn (Y. Wang).

1 Present address: Department of Environmental Science and Analytical Chemistry, Stockholm University, Stockholm, SE-10691, Sweden.
}

distribution and potential persistence in different matrices, bioaccumulation, and toxic properties (Friden et al., 2011; Houde et al., 2008; Iozza et al., 2008; Parera et al., 2013; Strid et al., 2013; Ueberschar et al., 2007; Warnasuriya et al., 2010). SCCPs are POPs candidates and are being considered for inclusion in the Stockholm Convention on POPs. The Persistent Organic Pollutants Review Committee (POPRC) has reviewed the draft risk profile for SCCPs and considered it fulfilled the criteria specified in Annex $\mathrm{E}$ of the Stockholm Convention at the eleventh meeting of the POPRC in October, 2015 (UNEP, 2015). China is now the largest CP producer and consumer in the world (Xu et al., 2014). The environmental occasions, fate, pattern files have been reported in different matrices in China (Harada et al., 2011; Wang et al., 2012,2014; Zeng et al., 2013; Zhao et al., 2013).

In recent years, considerable work has been performed to evaluate the distribution, environmental fate, and risk assessment of hazardous contaminants, such as dioxins, polychlorinated 
biphenyls (PCBs), polycyclic aromatic hydrocarbons (PAH), polybrominated diphenyl ethers (PBDEs), and other halogenated compounds, in e-waste dismantling areas in China (Fu et al., 2011a, 2013; Leung et al., 2015; Ni et al., 2010; Zhang et al. 2012, 2014). As a class of plasticizers, CPs are also widely used in electronic devices, and can be released into the environment through inappropriate e-waste recycling (Fiedler, 2010; OSPAR, 2009). Our previous work found high concentrations of SCCPs in soil from the area of Taizhou, southeastern China, due to e-waste dismantling activities (Yuan et al., 2010). Chen et al. (2011) and Wang et al. (2013) observed high CP concentrations in sediments from a highly industrialized, e-waste dismantling area in the Pearl River Delta, South China. Concentrations of SCCP in the muscles of terrestrial birds inhabiting this area were reported from 620 to $17,000 \mathrm{ng} / \mathrm{g}$ lipid. Differences in concentrations and homologue group patterns between resident and migratory bird species indicated that e-waste dismantling is a very important source of SCCPs to the ambient environment (Luo et al., 2015).

In the present study, paddy field soil, paddy seeds (Oryza sativa), and apple snails (Ampullariidae) inhabiting the paddy fields were collected in the e-waste dismantling area in Taizhou, southeastern China. The purposes are to investigate the compositional patterns of SCCPs in different matrices belonging to the same miniature paddy-field ecosphere and to assess the potential contamination risk to soil dwelling organisms and human from SCCPs due to ewaste dismantling behavior.

\section{Materials and methods}

\subsection{Chemical and reagents}

Chemical and reagent information is given in our previous work (Yuan et al., 2010).

\subsection{Sampling sites selecting and grouping}

Fengjiang is the e-waste dismantling center in Taizhou, Zhejiang Province, China (Ni et al., 2010). Large recycling firms are mainly located in the Fengjiang town with an area of $1.1 \mathrm{~km}^{2}$. Intensive dismantling works are also carried out in unauthorized familybased workshops and mini firms in the villages surrounding the center (Chi et al., 2014). As a result, the e-waste dismantling area covers a radius of approximate $20 \mathrm{~km}$ from the center. Small-scale paddy fields are scattered within this area and were selected as sampling sites. The size of individual paddy field ranged from $20 \times 30$ to $70 \times 150$ square meters. The sampling campaign was carried out in 2008 and 2010 and covered an area with a radius of approximate $65 \mathrm{~km}$ in four directions around the large dismantling factory in Fengjiang.

A total number of 32 individual soil samples, in addition to 28 apple snail samples and 34 paddy pooled samples were analyzed (each paddy sample was divided into hull and unpolished rice). Each paddy or surface soil sample $(0-23 \mathrm{~cm}$ depth) was a composite of five sub-samples from different farm lands within one sampling site. Each apple snail sample was a composite of 30 individuals collected from at least three sub-sampling sites. The diameters of the apple snails selected were approximately $3-5 \mathrm{~cm}$. Soft tissues from the apple snail samples were separated for instrumental analysis. Since paddy hulls and rice may have different transfer mechanism of contaminants (Fu et al., 2012), paddy seeds were separated into hulls and unpolished rice (rice for short) for analysis using a huller in the laboratory. All samples were freeze-dried, ground to fine powder, sealed in polyethylene bags, and kept at $4{ }^{\circ} \mathrm{C}$ until analysis.

In order to reduce errors from single sampling sites and to optimize the even distribution of matrices in each group, the samples were divided into six groups according to the sampling radius within the range of $0-5 \mathrm{~km}, 5-10 \mathrm{~km}, 10-15 \mathrm{~km}, 15-20 \mathrm{~km}$, 20-30 km, and 30-65 km from the town center (Fig. 1, Table S1). The discussion was made based on between-group comparison.

\subsection{Extraction and clean-up}

The sample pretreatment process was based on our previous work (Yuan, 2012; Yuan et al., 2010). Briefly, 2-8 g of the homogenized samples ( $2 \mathrm{~g}$ hulls, soil or snail samples, or $8 \mathrm{~g}$ rice) were mixed with $20 \mathrm{~g}$ anhydrous sodium sulfate and spiked with $1.0 \mathrm{ng}$ surrogate standard ${ }^{13} \mathrm{C}_{10}$-trans-chlordane. Next, the sample was extracted by accelerated solvent extraction (ASE) with a solvent mixture of hexane: dichloromethane $(1: 1 \mathrm{v} / \mathrm{v})$ at a temperature of $150{ }^{\circ} \mathrm{C}$ and pressure of 1500 psi. $2 \mathrm{~g}$ activated copper powder was added to the soil extract for sulfur removal and then filtered through approximately $5 \mathrm{~g}$ of anhydrous sodium sulfate. The extract was concentrated to approximately $2 \mathrm{~mL}$ by rotary evaporator and further cleaned in a multilayer silica-Florisil column that consisted of $3 \mathrm{~g}$ Florisil, $2 \mathrm{~g}$ activated silica gel, $5 \mathrm{~g} 30 \%$ (w/w) acid silica gel, and $4 \mathrm{~g}$ anhydrous sodium, from bottom to top. After precleaning with $50 \mathrm{~mL}$ hexane, the concentrated extract was loaded and then eluted by $40 \mathrm{~mL}$ of hexane and $100 \mathrm{~mL}$ of hexane/ dichloromethane $(1: 1, v / v)$. The second part of the eluent was further concentrated and solvent exchanged to cyclohexane to a final volume of $50 \mu \mathrm{L}$ (or $10 \mu \mathrm{L}$ for rice samples). Next, $10 \mathrm{ng} \varepsilon-\mathrm{HCH}$ in $10 \mu \mathrm{L}$ of cyclohexane was added for further instrument analysis.

\subsection{Instrumental analysis and quantification}

Instrumental analysis, identification, and quantification of SCCPs were based on our previous work (Zeng et al., 2011). Quantification analysis was performed on a 7890A gas chromatography coupled with a 7000B triple quadrupole mass spectrometer in the electron capture negative ionization (ECNI) mode using methane as the reagent gas (Agilent Technologies, USA).

The qualification and quantification were performed by comparing retention time, signal shape, and isotope ratio to other works (Reth and Oehme, 2004) with several modifications. A detailed description of the modified methods can be found in our previous work (Yuan et al., 2012). In order to improve detection, all monitored quantification ions for SCCPs and MCCPs were divided into four groups with four individual injections: $C_{10}$ and $C_{15}, C_{11}$ and $\mathrm{C}_{16}, \mathrm{C}_{12}$ and $\mathrm{C}_{17}, \mathrm{C}_{13}$ and $\mathrm{C}_{14}$.

\subsection{Analytical quality control}

All glassware was heated to $450{ }^{\circ} \mathrm{C}$ and rinsed with a mixture of hexane and dichloromethane prior to use. One laboratory blank was included among each batch of 10 samples. In general, levels of SCCPs in the procedural blanks were close to or under the limit of detection (LOD), which is estimated at $5 \mathrm{ng} / \mathrm{g}$ for total SCCPs. Therefore the final reported data was not blank-corrected. A $1+1$ SCCP standard mixture was prepared for recovery test from SCCP $55.5 \% \mathrm{Cl}$ and SCCP $63.0 \% \mathrm{Cl}$. The chlorine content of the standard mixture $(59.3 \% \mathrm{Cl})$ was close to the mean value of the samples in this study. Recoveries were accessed by spiking three sodium sulfate blanks and by spiking five rapeseed cooking oil samples. For spiked sodium sulfate blanks, the recoveries for ${ }^{13} \mathrm{C}_{10}$-trans-chlordane and SCCP standard mixture were in the range of $85 \%-100 \%$ and $76 \%-98 \%$, respectively. For spiked rapeseed oil samples, the recoveries were in the range of $89 \%-118 \%$ and $76 \%-108 \%$, respectively. The relative standard deviations ranged from $8 \%$ to $15 \%$ for recovery tests. The recoveries of ${ }^{13} \mathrm{C}_{10}$-trans-chlordane in the 


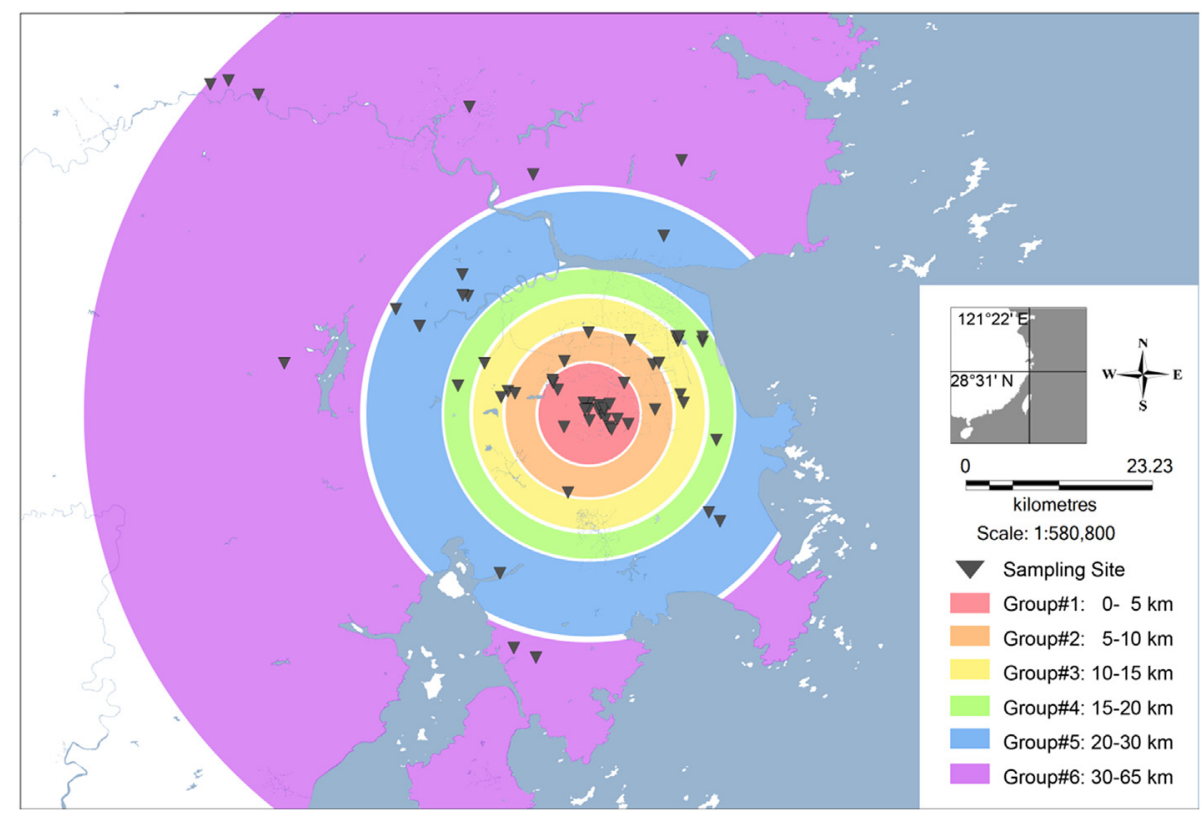

Fig. 1. Map of sampling sites and grouping areas in the Taizhou e-waste dismantling area.

samples ranged from $82 \%$ to $104 \%$. Recovery test on soil samples can be found in our previous work (Zeng et al., 2011).

\subsection{Statistical analyses}

Statistical analysis was carried out with SPSS 16.0 (SPSS Inc., 1989-2007). Linear regression was performed to evaluate spatial distribution of SCCPs, and statistical significance was accepted at $P<0.05$. Principal component analysis (PCA) was executed to project SCCP homologue group data onto two dimensions for comparison of the homologue distributions among different environmental matrices. To eliminate the impact of variable concentrations in these matrices, the primary data were normalized by logarithmic transformation for PCA analysis. Bivariate and partial correlation analyses were further executed to investigate the compositions and interactions among the homologue groups in different environmental matrices. The statistical significance was accepted at the level of 0.01 (2-tailed).

\subsection{Estimated daily intake (EDI)}

The EDI of SCCPs for local adults was calculated by the equation as follows (Fu et al., 2013):

$$
\begin{aligned}
\mathrm{EDI}= & \text { rice consumption }(\mathrm{g} / \text { day }) \\
& \times \sum \mathrm{SCCPs}(\mathrm{ng} / \mathrm{g}) / \text { average body weight }(\mathrm{kg}-\mathrm{bw})
\end{aligned}
$$

The average daily rice intake of local adults is considered to be $323 \mathrm{~g} /$ day, and the average body weight is $60 \mathrm{~kg}$ (Zheng et al., 2007; Zhong et al., 2006).

\section{Results}

SCCPs are found in all samples. Table 1 summarizes the total concentrations of SCCPs ( $\sum$ SCCPs) in different matrices. All concentrations are reported on a dry weight $(\mathrm{dw})$ basis. Detection frequency (DF) is used as a significant parameter in homologue group comparison among matrices, especially for homologue groups of low content. The DFs for each homologue group are shown in Table S2 of the Supplementary Material.

\subsection{SCCPs in soil}

$\sum$ SCCPs in the paddy field soils for all distance groups range from 30.4 to $530 \mathrm{ng} / \mathrm{g} \mathrm{dw}$ with an average value of $80.2 \mathrm{ng} / \mathrm{g} \mathrm{dw}$. $\mathrm{C}_{10}$ and $\mathrm{C}_{11}$ homologues are the two most predominant carbon chain groups in the soil, accounting for $32.1 \pm 5.4 \%$ and $31.9 \pm 3.1 \%$ of $\sum$ SCCPs. They are significantly higher than $C_{12}$ and $C_{13}$ homologue groups, which account for only $20.5 \pm 2.4 \%$ and $15.5 \pm 3.5 \%$ of $\sum$ SCCPs (Fig. 2). Among the chlorine homologue groups (Fig. S1), $6 \mathrm{Cl}$ groups are the most predominant homologues (40.5 $\pm 3.3 \%$ ), followed by $7 \mathrm{Cl}(26.5 \pm 3.4 \%)$ and $5 \mathrm{Cl}(25.1 \pm 5.6 \%)$. The highly chlorinated homologues ( $\geq 8 \mathrm{Cl}$ groups) only account for less than $8 \%$ of $\sum$ SCCPs; however, DFs for $\mathrm{C}_{n} \mathrm{Cl}_{8}(\mathrm{n}=10-13$, similarly hereinafter) and higher chlorinated homologues are greater than $90 \%$ except for $\mathrm{C}_{11} \mathrm{Cl}_{10} . \mathrm{C}_{10} \mathrm{Cl}_{6}$ is the most abundant homologue group, the percentage content of which accounts for $16.7 \pm 3.7 \%$ of the total SCCPs, followed by $\mathrm{C}_{11} \mathrm{Cl}_{6}(10.5 \pm 1.7 \%)$ and $\mathrm{C}_{10} \mathrm{Cl}_{7}(10.1 \pm 2.1 \%)$.

The average $\sum$ SCCPs in soil in this study is lower than in paddy soil from the Chinese Liaohe River Basin (110 $\pm 44 \mathrm{ng} / \mathrm{g}$ ) (Gao et al. 2012). ESCCPs in soil in the sampling area are generally lower than in Chinese farmland soil irrigated with wastewater (159.9-1450 ng/g) (Zeng et al., 2011). The levels of short and medium chain compounds were reported to be less than $100 \mathrm{ng} / \mathrm{g} \mathrm{dw}$

Table 1

SCCP concentrations in different matrices collected from the Taizhou e-waste

\begin{tabular}{|c|c|c|c|c|c|c|}
\hline \multirow[t]{2}{*}{ Matrix } & \multicolumn{3}{|c|}{ Concentration (ng/g dw) } & \multicolumn{3}{|c|}{ Chlorination degree $(\mathrm{Cl} \%, \mathrm{w} / \mathrm{w}$} \\
\hline & Min & Max & Mean & Min & Max & Mean \\
\hline Soil & 30.4 & 530 & 80.2 & 56.8 & 60.0 & 58.8 \\
\hline Hull & 47.6 & 387 & 95.2 & 57.2 & 62.2 & 59.5 \\
\hline Rice & 4.90 & 55.1 & 17.6 & 58.1 & 61.7 & 59.1 \\
\hline Snail & 137 & 821 & 314 & 57.7 & 61.3 & 59.7 \\
\hline
\end{tabular}
dismantling area. 

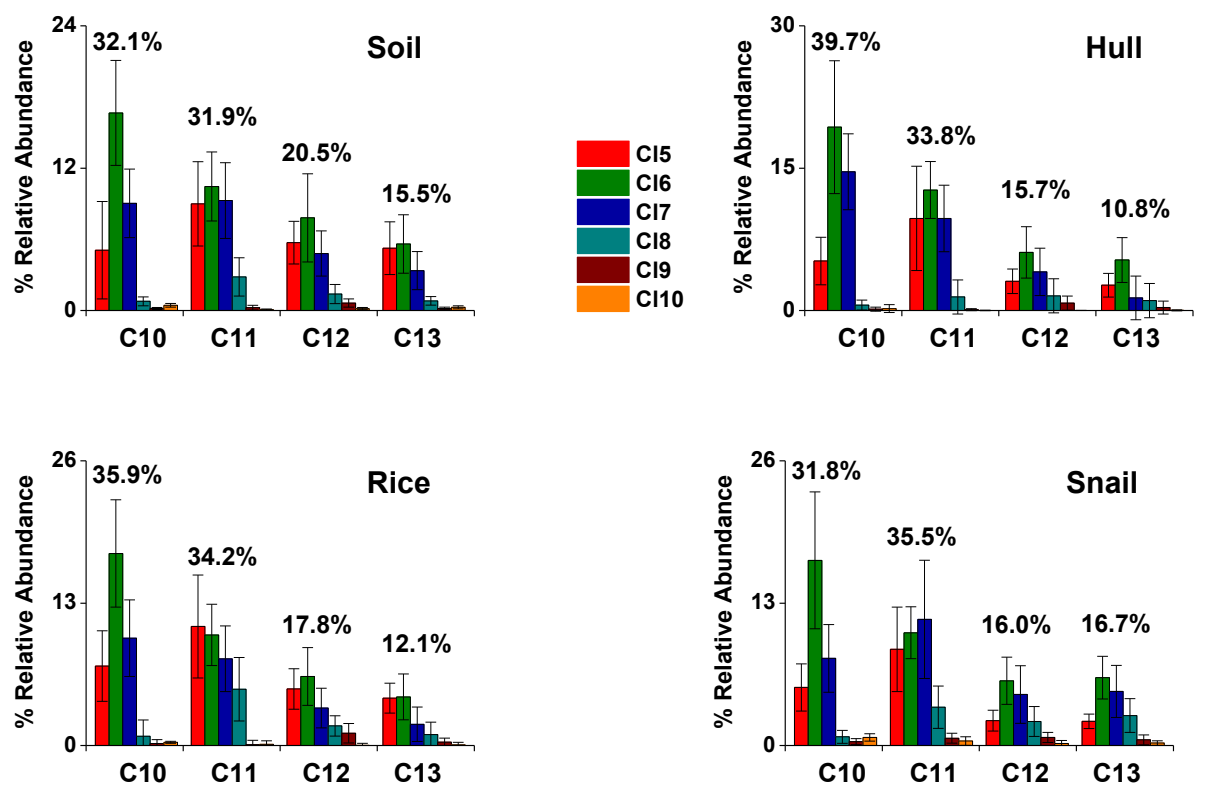

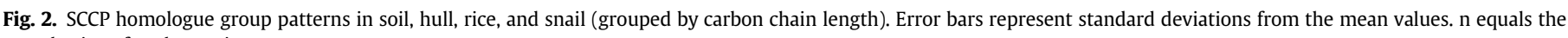
sample size of each matrix.

in the soil of industrial areas in England and Wales (Nicholls et al., 2001). The concentrations in the soil within $10 \mathrm{~km}$ from the sampling center are generally higher than this level (Fig. S2). The carbon chain distribution pattern, $C_{10}>C_{11}>C_{12}>C_{13}$, is similar to the paddy soil in Liaohe River Basin, but the latter had a higher percentage content of $5 \mathrm{Cl}$ homologues.

SCCP concentrations in soil in this study were higher than concentrations of some other flame retardants investigated in the same area such as PCBs and PBDEs. The concentrations of 25 PCBs and 13 PBDEs have been reported in the soils in the Taizhou area in 2008, which ranged from 0.48 to $90.1 \mathrm{ng} / \mathrm{g}$ and $0.06-31.2 \mathrm{ng} / \mathrm{g}$ (Fu et al., 2011b).

We also compared the concentrations of CPs in soils collected in 2008 using EI-MS ${ }^{2}$ (Yuan et al., 2010) to the $\sum$ SCCPs results of this work. In the same batch of soil samples, CP concentrations using EI$\mathrm{MS}^{2}$ were in the range of $911-4730 \mathrm{ng} / \mathrm{g}$ dw with an average of $2670 \mathrm{ng} / \mathrm{g} \mathrm{dw}$, while in this work, $\sum$ SCCPs in soil samples ranged from 57.1 to $530 \mathrm{ng} / \mathrm{g} \mathrm{dw}$. This difference may be due to the different quantitative methods. EI-MS ${ }^{2}$ can analyze total CPs with the advantage of ion selection; however, it fails to distinguish CPs with different numbers of carbon and chlorine atoms. The ECNI method can selectively quantify the concentrations of $C_{10}-C_{13}$ homologues with 5-10 substitute chlorines, but inevitable errors occur when using ECNI-MS for detecting lowly chlorinated alkanes with less than five chlorine atoms. The comparison indicates that beside SCCPs, there are also MCCPs and even LCCPs existing in the e-waste dismantling areas.

\subsection{SCCPs in paddy seeds}

$\sum$ SCCPs levels in the hulls are comparable to soils with a range of $47.6-387 \mathrm{ng} / \mathrm{g} \mathrm{dw}$ and an average concentration of $95.2 \mathrm{ng} / \mathrm{g} \mathrm{dw}$. Rice shows the lowest concentrations of SCCPs among the four types of samples with a range of 4.90-55.1 $\mathrm{ng} / \mathrm{g} \mathrm{dw}$ and an average value of $17.6 \mathrm{ng} / \mathrm{g} \mathrm{dw}$. Carbon chain lengths and chlorine distribution patterns show no significant differences between hull and rice or between paddy and soil samples. However, highly chlorinated homologues have significantly lower DFs in hulls and rice samples than soil samples; for example, the DFs for $10 \mathrm{Cl}$ in hull, rice and soil samples are $31.6 \%, 26.5 \%$ and $89.1 \%$, respectively. $\sum$ SCCPs values in rice are significantly higher than those found in grain crop samples in Japan (2.5 ng/g dw or $470 \mathrm{ng} / \mathrm{g}$ lipid), where rice was the major constitute of the samples (79.5\% by weight) (Tsunemi, 2010). In those grain crops, $C_{10}$ homologue groups were also the most dominant, followed by $\mathrm{C}_{11}$; all $\mathrm{C}_{\mathrm{n}} \mathrm{Cl}_{10}$ homologue groups were below LOD.

Overall, the average $\sum$ SCCPs in hulls is higher than in rice by about a factor of five. Similar differences between hull and corresponding rice grain concentrations were also found in a study of PCDD/F (Fu et al., 2012). So far there was no report about SCCPs in hulls from the other places. Hulls have a relatively large surface area, which were considered as a suitable passive air sampler (Fu et al., 2012). We thus compared SCCPs in hulls with the one in air samples from Beijing. The homologue group patterns are similar that in both studies higher chlorinated homologues were mostly below the detection limits (Wang et al., 2012). Spruce needles accumulate air pollutants due to their large surface area and epicuticular wax layer. $\sum$ SCCPs in hulls in this study are within a similar range of total CPs in spruce needles from the Alps (Iozza et al., 2009).

\subsection{SCCPs in snail}

$\sum$ SCCPs in the apple snail samples range from 137 to $821 \mathrm{ng} / \mathrm{g}$ $\mathrm{dw}$, which are the highest values among the four matrices tested. The DFs for all homologue groups are higher than $90 \%$ in the snail samples.

Unlike the other matrices in our study, the SCCP carbon chain pattern in apple snails does not follow the $C_{10}>C_{11}>C_{12}>C_{13}$ trend. $C_{11}$ is the predominant carbon chain group of the apple snail samples and accounts for $36.0 \pm 3.4 \%$ of $\sum$ SCCPs, followed by $C_{10}$ at $31.2 \pm 6.4 \%$. Similar differences were found in a study of bivalves and the sediments they inhabited(Ma et al., 2014). Among the chlorine categories, $6 \mathrm{Cl}$ and $7 \mathrm{Cl}$ groups are the two most abundant homologue groups, similar to the previously reported composition patterns of SCCPs in gastropods (Rapana venosa and Neverita didyma) collected from China's Bohai Sea (Yuan et al., 2012). 


\section{Discussion}

\subsection{Comparison among the matrices}

\subsubsection{Homologue percentage ratio and concentration ratio}

The ratios of total SCCP concentrations were calculated between soil and the other matrices within individual sampling groups. Total SCCP concentrations in hull, rice and snail are $1.3 \pm 0.3,0.24 \pm 0.18$ and $5.2 \pm 4.0$ times the one in soil, respectively. $\sum$ SCCPs in hull and snail are higher than $\sum$ SCCPs in soil. To further investigate SCCP transfer behaviors among the different matrices, both percentage ratios and concentration ratios for carbon chain and chlorine categories in paddy-to-soil and snail-tosoil comparisons are shown in Fig. 3. The ratios were calculated homologue by homologue, in order to remove the influence of the response factor differences among SCCP homologue groups. Among the carbon categories (Fig. 3A1), the average percentages of $\mathrm{C}_{10}$ and $\mathrm{C}_{11}$ homologues in both hulls and rice are higher than in soil. According to the concentration ratios shown in Fig. 3B1, the accumulation potential of SCCP homologues in hulls decreased with carbon chain length. Among the carbon categories, the homologue composition in apple snails exhibits no significant correlation with the homologue composition in soils, although the abundances of all homologue groups in snails are higher than those in soils. As shown in the chlorine categories (Fig. 3A2), apple snails have higher percentages of $\geq 7 \mathrm{Cl}$ homologues than soils. For the snail-to-soil comparison, the percentage ratios and concentration ratios generally increase with the number of substitute chlorines. Considering the correlations between carbon chain length/chlorine number of CPs and their physical properties (Drouillard et al., 1998; Gluge et al., 2013; Hilger et al., 2011), the paddy samples are more likely to accumulate relatively volatile SCCP homologues, whereas the apple snail samples lipophilic homologues with higher values of $\log K_{\text {ow }}$.

\subsubsection{Principal component analysis}

PCA shows a visual representation of the main characteristics of the relationship among the SCCP homologue groups in different environmental matrices. Samples of the same matrix are clustering in the score plot (Fig. 4B), which indicates that accumulation behaviors are different from individual matrices.

The first two principal components account for $71.2 \%$ of the total variance. The results from the loading plot show that SCCP homologue groups are mainly distributed in the first quadrant of the scatter plot (Fig. 4A). The homologues with less substitute chlorines are closer to the $\mathrm{x}$-axis and the counterparts of the higher chlorinated homologues are closer to the y-axis. The score plot shows that all the data cluster together in four groups depending on their species (Fig. 4B). The dots representing the apple snail and the rice samples are distributed in the first and third quadrant, indicating the highest and lowest concentrations of SCCPs, respectively, among the four investigated environmental matrices. The dots for the hull samples are distributed in the second and fourth quadrant; the dots for the soil samples are closest to the origin. The overlapped areas between the clusters of hull and soil samples indicate similar homologue patterns of SCCPs in these two matrices, implying that they might share the same sources of SCCPs.

\subsubsection{Correlation analysis}

To further investigate the compositions and interactions among the homologue groups in different environmental matrices, bivariate and partial correlation analyses were carried out for SCCP homologue groups in each matrix (Table S3). Hull, rice and apple snail samples are all significantly correlated with soil samples at the 0.01 significance level.

Uegaki et al. (2006) concluded that soil is not the only possible contamination pathways for dioxins in rice. We further perform partial correlation analysis (Table S4) with soil as the control variable to exclude factor interaction. Rice significantly relates to hulls, indicating that these two samples shared contamination sources. This relationship could have been attributable to particulate matter, atmospheric gases or slight interactions during the hulling process. In our study, snails do not show a significant relationship to either rice or hulls. The uptake rates for different homologues may be different as well as the potential biotransformation of SCCPs by the snail. In addition, apple snails primarily feed on young rice seedlings and weeds (Halwart, 1994; Wada, 2004), which may have different contamination patterns from rice seeds.
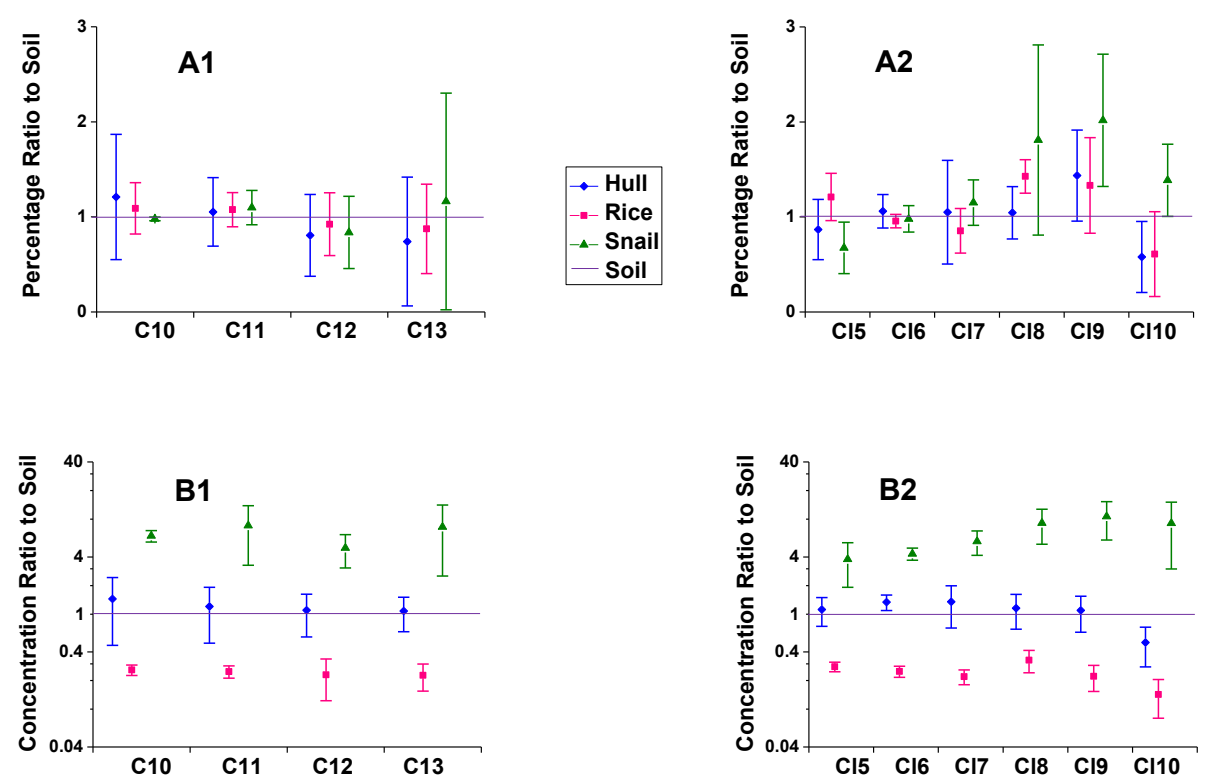

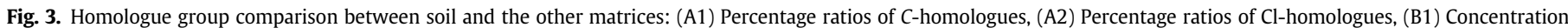

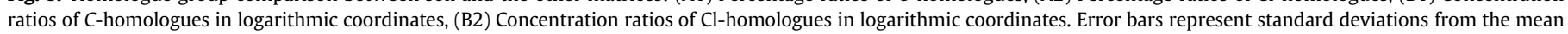
values. $n$ equals the number of sampling groups times the number of investigated SCCP homologue groups, i.e., $n=6 \times 24=144$. 


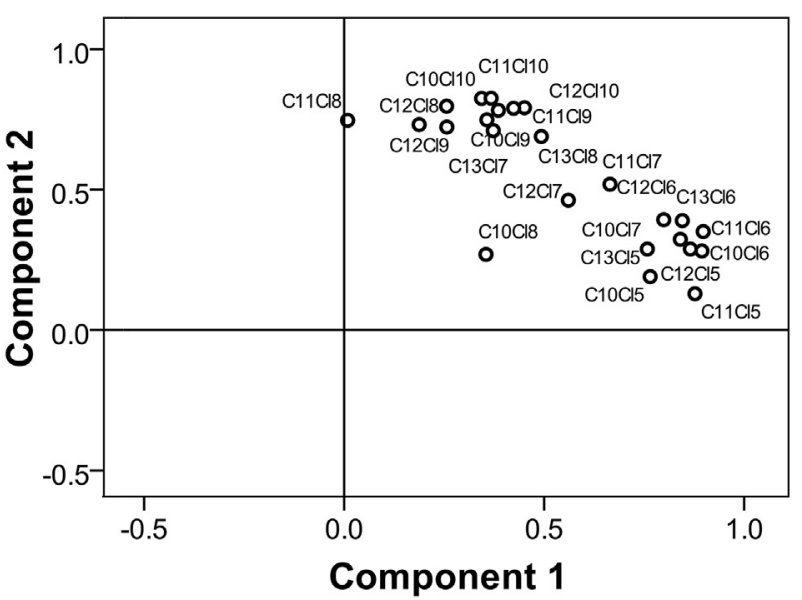

(A)

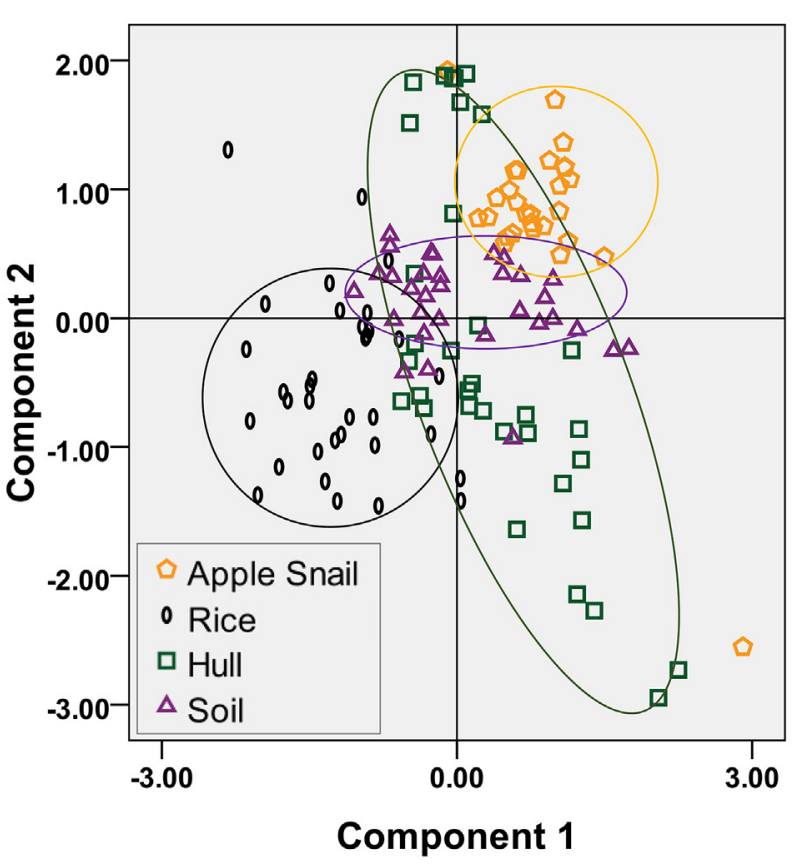

(B)

Fig. 4. PCA loading plot (A) and score plot (B) based on the logarithmically transformed database.

The correlation analyses were also carried out between different homologue groups within each matrix. The results are shown in Table S5 to S8 of the Supplementary Material. In the hulls, significant negative linear relationships are found between $\mathrm{C}_{10} \mathrm{Cl}_{5-6}$ and $\mathrm{C}_{11} \mathrm{Cl}_{6-9}, \mathrm{C}_{10} \mathrm{Cl}_{5-6}$ and $\mathrm{C}_{12-13} \mathrm{Cl}_{6-10}, \mathrm{C}_{11} \mathrm{Cl}_{5-6}$ and $\mathrm{C}_{12-13} \mathrm{Cl}_{8-10}$, while significant positive linear relationships are found between $\mathrm{C}_{11} \mathrm{Cl}_{9-10}$ and $\mathrm{C}_{12-13} \mathrm{Cl}_{7-10}, \mathrm{C}_{12} \mathrm{Cl}_{8,10}$ and $\mathrm{C}_{11,13} \mathrm{Cl}_{7-10}$. The primary correlations between the homologue groups in soils are similar to those in hulls, implying the same possible SCCPs sources. Generally, hulls can absorb organic pollutants from the air or adsorb the particles by dry deposition (Fu et al., 2012). Soil is an important source of particles in the air, which might influence the concentrations and homologue patterns of SCCPs in the hulls.

Correlation analysis of the SCCP homologue groups in apple snails shows significant negative relationships between $\mathrm{C}_{10} \mathrm{Cl}_{5-6}$ and $\mathrm{C}_{11,13} \mathrm{Cl}_{6-9}$, and $\mathrm{C}_{11} \mathrm{Cl}_{5}$ and $\mathrm{C}_{12} \mathrm{Cl}_{8}$, while significant positive relationships are found between $\mathrm{C}_{10} \mathrm{Cl}_{9-10}$ and $\mathrm{C}_{11-13} \mathrm{Cl}_{9,10}, \mathrm{C}_{11} \mathrm{Cl}_{8-10}$ and $\mathrm{C}_{13} \mathrm{Cl}_{7-10}, \mathrm{C}_{12} \mathrm{Cl}_{8,10}$ and $\mathrm{C}_{13} \mathrm{Cl}_{7-10}$. Since the correlations in snail samples are similar to those in the soil samples, SCCPs in the snails may partly come from direct contact with the soil.

\subsection{Spatial distributions in different matrices}

There were negative correlations between the concentrations of SCCPs in four matrices and the distances from the town center in this study (Fig. S2), but the relationships were not significant $(\mathrm{R}=0.25-0.32, \mathrm{P}=0.05-0.17)$. The highest concentrations of SCCPs in soil and snail samples are not observed in Group 1, which included the samples collected from Fengjiang, but in Group 2 and 3 , respectively. The SCCP contamination area is consistent with the e-waste dismantling area which were reported within approximate $20 \mathrm{~km}$ from the center (Chi et al., 2014). The consistent SCCP patterns in four individual matrices (Fig. 2, Fig. S1) indicate that the sampling area was contaminated by the same kind of source. The results suggest that both the recycling center Fengjiang and the unauthorized workshops and firms surrounding it contributed to SCCP pollution in the sampling area. Scattered workshops and firms did not significantly alter the contamination pattern of SCCPs since SCCP patterns of these point sources are similar, but disturbed the spatial distributions of SCCPs, especially to the matrices soil and snail. These two matrices might be easier to be affected by the pollution source nearby than the paddy seeds hung in the air.

There were significant negative linear correlations between $\mathrm{Cl} \%$ in soil and snail samples and distances from the center Fengjiang $(\mathrm{P}<0.05) . \mathrm{Cl} \%$ in rice samples also showed a negative linear correlation with distances from the Fengjiang center, although the significance was $\mathrm{P}=0.06$. Interestingly, the $\mathrm{Cl} \%$ in hull samples showed a positive trend with distances from the Fengjiang center, but the significance was $\mathrm{P}=0.24$ (Fig. S3). It is because the total percentage of $\mathrm{C}_{10-11}$ homologues in hull samples increases with distances from the Fengjiang center (Fig. S4). This makes the average molecular weight of SCCPs in the hulls of remote groups lower than that in core regions. Our previous works on PCBs and PBDEs in hulls in the same sampling area observed that the large surface area of hulls can readily adsorb organic pollutants from the atmosphere (Fu et al., 2012), which might have been responsible for the higher $\mathrm{Cl} \%$ and concentration rebounding that occurred in hulls in the remote groups (Group 5 and 6).

\subsection{Ecological risk and human exposure assessment}

The highest concentration in this study is still below the predicted no-effect concentration of $5280 \mathrm{ng} / \mathrm{g}$ for soil dwelling organisms (Bezchlebova et al., 2007). This finding indicates that the level of SCCPs alone poses no significant ecological risks for the soil environment.

Hulls are part of the feed formulation of pigs and chickens on local farms. SCCPs could enter the food chain and be transferred to local meat consumers through dietary uptake as the other contaminants (Luo et al., 2009). Rice is the staple carbohydrate for local residents. The EDI of SCCPs in the study is estimated from 26.4 to $297 \mathrm{ng} / \mathrm{kg}$-bw/day from rice intake only. Data concerning $\sum$ SCCPs in the human diet were reported in the range of $8.5-28 \mathrm{ng} / \mathrm{g}$ $(8500-28,000 \mathrm{pg} / \mathrm{g})$ in Beijing in the same year as our sampling. The geometric mean of the dietary intake of SCCPs was $620 \mathrm{ng} / \mathrm{kg}$ bw/day(Harada et al., 2011). Considering that the average rice intake is only $27.3 \%$ (in weight) of the local diet (Zhong et al., 2006), and due to high probabilities of biomagnification or bioaccumulation in pork and chickens, higher levels of dietary exposure to SCCPs are suspected for people living within $20 \mathrm{~km}$ of the 
contamination center.

In an evaluation by the International Agency for Research on Cancer (IARC), $\mathrm{C}_{12}$ groups with $60 \%$ chlorination degree are possible carcinogens in humans (IARC, 1990). In our study, the average degree of chlorination within a $20 \mathrm{~km}$ radius for snails was approximately $59.9 \%$, while rice was $59.2 \%$. Because apple snails are also listed on the local menu, eating snails would not only increase SCCPs intake but also raise potential health risk.

\section{Conclusion}

SCCPs were found in soil, paddy seeds and apple snails collected from the e-waste dismantling area and the surrounding area in Taizhou. Paddy seeds tend to accumulate SCCP homologues with shorter carbon chain length, and snails tend to accumulate SCCP homologues with more substituted chlorines. Local people are potentially exposed to SCCPs via many possible pathways, such as dietary intake and air inhalation. Transportation of SCCPs was suspected via air according to spatial analysis. Air monitoring is thus expected in future studies both for the clarification and for evaluation airborne SCCP contamination in the dismantling area.

\section{Acknowledgements}

Funding: This work was supported by the National Basic Research Program of China (2015CB453102), the National Natural Science Foundation of China (21321004), and Strategic Priority Research Program of the Chinese Academy of Sciences (XDB14010400, YSW2013A01).

\section{Appendix A. Supplementary data}

Supplementary data related to this article can be found at http:// dx.doi.org/10.1016/j.envpol.2016.10.009.

\section{References}

Bayen, S., Obbard, J.P., Thomas, G.O., 2006. Chlorinated paraffins: a review of analysis and environmental occurrence. Environ. Int. 32, 915-929.

Bezchlebova, J., Cernohlavkova, J., Kobeticova, K., Lana, J., Sochova, I., Hofman, J., 2007. Effects of short-chain chlorinated paraffins on soil organisms. Ecotoxicol. Environ. Saf. 67, 206-211.

Chen, M.Y., Luo, X.J., Zhang, X.L., He, M.J., Chen, S.J., Mai, B.X., 2011. Chlorinated paraffins in sediments from the Pearl River Delta, South China: spatial and temporal distributions and implication for processes. Environ. Sci. Technol. 45, 9936-9943.

Chi, X.W., Wang, M.Y.L., Reuter, M.A., 2014. E-waste collection channels and household recycling behaviors in Taizhou of China. J. Clean. Prod. 80, 87-95.

Drouillard, K.G., Tomy, G.T., Muir, D.C.G., Friesen, K.J., 1998. Volatility of chlorinated n-alkanes (C-10-C-12): vapor pressures and Henry's law constants. Environ. Toxicol. Chem. 17, 1252-1260.

Fiedler, H., 2010. Short-chain chlorinated paraffins: production, use and international regulations. In: Boer, J. (Ed.), Chlorinated Paraffins. Springer, Berlin Heidelberg, pp. 1-40.

Friden, U.E., McLachlan, M.S., Berger, U., 2011. Chlorinated paraffins in indoor air and dust: concentrations, congener patterns, and human exposure. Environ. Int. 37, 1169-1174.

Fu, J., Wang, T., Wang, P., Qu, G., Wang, Y., Zhang, Q., Zhang, A., Jiang, G., 2012. Temporal trends (2005-2009) of PCDD/Fs, PCBs, PBDEs in rice hulls from an ewaste dismantling area after stricter environmental regulations. Chemosphere $88,330-335$.

Fu, J., Wang, Y., Zhang, A., Zhang, Q., Zhao, Z., Wang, T., Jiang, G., 2011a. Spatial distribution of polychlorinated biphenyls (PCBs) and polybrominated biphenyl ethers (PBDEs) in an e-waste dismantling region in Southeast China: use of apple snail (Ampullariidae) as a bioindicator. Chemosphere 82, 648-655.

Fu, J., Zhang, A., Wang, T., Qu, G., Shao, J., Yuan, B., Wang, Y., Jiang, G., 2013. Influence of e-waste dismantling and its regulations: temporal trend, spatial distribution of heavy metals in rice grains, and its potential health risk. Environ. Sci. Technol. 47, 7437-7445.

Fu, J.J., Wang, Y.W., Zhang, A.Q., Zhang, Q.H., Zhao, Z.S., Wang, T., Jiang, G.B., 2011b. Spatial distribution of polychlorinated biphenyls (PCBs) and polybrominated biphenyl ethers (PBDEs) in an e-waste dismantling region in Southeast China: use of apple snail (Ampullariidae) as a bioindicator. Chemosphere 82, 648-655.
Gao, Y., Zhang, H., Su, F., Tian, Y., Chen, J., 2012. Environmental occurrence and distribution of short chain chlorinated paraffins in sediments and soils from the Liaohe River Basin, P. R. China. Environ. Sci. Technol. 46, 3771-3778.

Gluge, J., Bogdal, C., Scheringer, M., Buser, A.M., Hungerbuhler, K., 2013. Calculation of physicochemical properties for short- and medium-chain chlorinated paraffins. J. Phys. Chem. Reference Data 42.

Halwart, M., 1994. The golden apple snail Pomacea canaliculata in Asian rice farming systems: present impact and future threat. Int. J. Pest Manag. 40, 8.

Harada, K.H., Takasuga, T., Hitomi, T., Wang, P., Matsukami, H., Koizumi, A., 2011 Dietary exposure to short-chain chlorinated paraffins has increased in Beijing, China. Environ. Sci. Technol. 45, 7019-7027.

Hilger, B., Fromme, H., Volkel, W., Coelhan, M., 2011. Effects of chain length, chlorination degree, and structure on the octanol-water partition coefficients of polychlorinated n-alkanes. Environ. Sci. Technol. 45, 2842-2849.

Houde, M., Muir, D.C., Tomy, G.T., Whittle, D.M., Teixeira, C., Moore, S., 2008. Bioaccumulation and trophic magnification of short- and medium-chain chlorinated paraffins in food webs from Lake Ontario and Lake Michigan. Environ. Sci. Technol. 42, 3893-3899.

IARC, 1990. Chlorinated Paraffins. International Agency for Research on Cancer.

Iozza, S., Muller, C.E., Schmid, P., Bogdal, C., Oehme, M., 2008. Historical profiles of chlorinated paraffins and polychlorinated biphenyls in a dated sediment core from Lake Thun (Switzerland). Environ. Sci. Technol. 42, 1045-1050.

Iozza, S., Schmid, P., Oehme, M., Bassan, R., Belis, C., Jakobi, G., Kirchner, M., Schramm, K.W., Krauchi, N., Moche, W., Offenthaler, I., Weiss, P., Simoncic, P., Knoth, W., 2009. Altitude profiles of total chlorinated paraffins in humus and spruce needles from the Alps (MONARPOP). Environ. Pollut. 157, 3225-3231.

Leung, A.O., Cheung, K.C., Wong, M.H., 2015. Spatial distribution of polycyclic aromatic hydrocarbons in soil, sediment, and combusted residue at an e-waste processing site in southeast China. Environ. Sci. Pollut. Res. 22, 8786-8801.

Luo, X.-J., Sun, Y.-X., Wu, J.-P., Chen, S.-J., Mai, B.-X., 2015. Short-chain chlorinated paraffins in terrestrial bird species inhabiting an e-waste recycling site in South China. Environ. Pollut. 198, 41-46.

Luo, X.J., Liu, J., Luo, Y., Zhang, X.L., Wu, J.P., Lin, Z., Chen, S.J., Mai, B.X., Yang, Z.Y., 2009. Polybrominated diphenyl ethers (PBDEs) in free-range domestic fowl from an e-waste recycling site in South China: levels, profile and human dietary exposure. Environ. Int. 35, 253-258.

Ma, X., Chen, C., Zhang, H., Gao, Y., Wang, Z., Yao, Z., Chen, J., 2014. Congener-specific distribution and bioaccumulation of short-chain chlorinated paraffins in sediments and bivalves of the Bohai Sea, China. Mar. Pollut. Bull. 79, 299-304.

Ni, H.G., Zeng, H., Tao, S., Zeng, E.Y., 2010. Environmental and human exposure to persistent halogenated compounds derived from e-waste in China. Environ. Toxicol. Chem. 29, 1237-1247.

Nicholls, C.R., Allchin, C.R., Law, R.J., 2001. Levels of short and medium chain length polychlorinated n-alkanes in environmental samples from selected industrial areas in England and Wales. Environ. Pollut. 114, 415-430.

OSPAR, 2009. Background document on short chain chlorinated paraffins. In: O. Commission (Ed.), Hazardous Substances, p. 65.

Parera, J., Abalos, M., Santos, F.J., Galceran, M.T., Abad, E., 2013. Polychlorinated dibenzo-p-dioxins, dibenzofurans, biphenyls, paraffins and polybrominated diphenyl ethers in marine fish species from Ebro River Delta (Spain). Chemosphere 93, 499-505.

Reth, M., Oehme, M., 2004. Limitations of low resolution mass spectrometry in the electron capture negative ionization mode for the analysis of short- and medium-chain chlorinated paraffins. Anal. Bioanal. Chem. 378, 1741-1747.

Strid, A., Bruhn, C., Sverko, E., Svavarsson, J., Tomy, G., Bergman, A., 2013. Brominated and chlorinated flame retardants in liver of Greenland shark (Somniosus microcephalus). Chemosphere 91, 222-228.

Tsunemi, K., 2010. Risk Assessment of Short-Chain Chlorinated Paraffins in Japan. Springer-Verlag.

Ueberschar, K.H., Danicke, S., Matthes, S., 2007. Dose-response feeding study of short chain chlorinated paraffins (SCCPs) in laying hens: effects on laying performance and tissue distribution, accumulation and elimination kinetics. Mol. Nutr. Food Res. 51, 248-254.

Uegaki, R., Seike, N., Otani, T., 2006. Polychlorinated dibenzo-p-dioxins, dibenzofurans, and dioxin-like polychlorinated biphenyls in rice plants: possible contaminated pathways. Chemosphere 65, 1537-1543.

UNEP, 2015. UNEP/POPS/POPRC.11/4.

Wada, T., 2004. Strategies for controlling the apple snail Pomacea canaliculata (Lamarck) (Gastropoda : Ampullariidae) in Japanese direct-sown paddy fields. Jarq-Japan Agric. Res. Q. 38, 75-80.

Wang, T., Han, S., Yuan, B., Zeng, L., Li, Y., Wang, Y., Jiang, G., 2012. Summer-winter concentrations and gas-particle partitioning of short chain chlorinated paraffins in the atmosphere of an urban setting. Environ. Pollut. 171, 38-45.

Wang, X.T., Wang, X.K., Zhang, Y., Chen, L., Sun, Y.F., Li, M., Wu, M.H., 2014. Shortand medium-chain chlorinated paraffins in urban soils of Shanghai: spatial distribution, homologue group patterns and ecological risk assessment. Sci. Total Environ. 490C, 144-152.

Wang, Y., Li, J., Cheng, Z., Li, Q., Pan, X., Zhang, R., Liu, D., Luo, C., Liu, X., Katsoyiannis, A., Zhang, G., 2013. Short- and medium-chain chlorinated paraffins in air and soil of subtropical terrestrial environment in the pearl river delta, South China: distribution, composition, atmospheric deposition fluxes, and environmental fate. Environ. Sci. Technol. 47, 2679-2687.

Warnasuriya, G.D., Elcombe, B.M., Foster, J.R., Elcombe, C.R., 2010. A Mechanism for the induction of renal tumours in male Fischer 344 rats by short-chain chlorinated paraffins. Arch. Toxicol. 84, 233-243. 
Xu, C., Xu, J.H., Zhang, J.B., 2014. Emission inventory prediction of short chain chlorinated paraffins (SCCPs) in China (in Chinese). Acta Sci Nat Univ Pekin.

Yuan, B., 2012. Analytical method and environmental behavior of short-chain chlorinated paraffins (in Chinese). In: Research Center for Eco-Environmental Sciences. Chinese Academy of Sciences, Beijing, p. 157.

Yuan, B., Wang, T., Zhu, N., Zhang, K., Zeng, L., Fu, J., Wang, Y., Jiang, G., 2012. Short chain chlorinated paraffins in mollusks from coastal waters in the Chinese Bohai Sea. Environ. Sci. Technol. 46, 6489-6496.

Yuan, B., Wang, Y.W., Fu, J.J., Zhang, Q.H., Jiang, G.B., 2010. An analytical method for chlorinated paraffins and their determination in soil samples. Chin. Sci. Bull. 55, 7.

Zeng, L., Chen, R., Zhao, Z., Wang, T., Gao, Y., Li, A., Wang, Y., Jiang, G., Sun, L., 2013. Spatial distributions and deposition chronology of short chain chlorinated paraffins in marine sediments across the Chinese Bohai and Yellow Seas. Environ. Sci. Technol. 47, 11449-11456.

Zeng, L., Wang, T., Han, W., Yuan, B., Liu, Q., Wang, Y., Jiang, G., 2011. Spatial an vertical distribution of short chain chlorinated paraffins in soils from wastewater irrigated farmlands. Environ. Sci. Technol. 45, 2100-2106.

Zhang, Q. Ye, J.J. Chen, J.Y. Xu, H.J., Wang, C., Zhao, M.R., 2014. Risk assessment of polychlorinated biphenyls and heavy metals in soils of an abandoned e-waste site in China. Environ. Pollut. 185, 258-265.

Zhang, T., Huang, Y.R., Chen, S.J., Liu, A.M., Xu, P.J., Li, N., Qi, L., Ren, Y., Zhou, Z.G. Mai, B.X., 2012. PCDD/Fs, PBDD/Fs, and PBDEs in the air of an e-waste recycling area (Taizhou) in China: current levels, composition profiles, and potential cancer risks. J. Environ. Monit. 14, 3156-3163.

Zhao, Z, Li, H., Wang Y, Li, G, Cao, Y, Zeng L, Lan, J, Wang T, Jiang G, 2013. Source and migration of short-chain chlorinated paraffins in the coastal East China Sea using multiproxies of marine organic geochemistry. Environ. Sci. Technol. 47, 5013-5022.

Zheng, N., Wang O.C., Zhang, X.W, Zheng D.M., Zhang Z.S., Zhang, S.Q, 2007. Population health risk due to dietary intake of heavy metals in the industrial area of Huludao city, China. Sci. Total Environ. 387, 96-104.

Zhong, J., Yu, M., Liu, L., Chen, Y., Hu, R., Gong, W., 2006. Study on the dietary nutrition intake level in Zhejiang Province (in Chinese). Dis. Surveill. 21, 3. 